\title{
The dependence of the critical energy density and hot-spot temperature on the radius of metal nanoparticles in PETN
}

\author{
A. A. Zvekov ${ }^{2}$, A. P. Nikitin ${ }^{2}$, E. V. Galkina ${ }^{1}$, A. V. Kalenskii ${ }^{1}$ \\ ${ }^{1}$ Kemerovo state University, Kemerovo, 650000, Russia \\ ${ }^{2}$ Federal Research Center of coal and coal chemistry SB RAS \\ (Institute of Coal Chemistry and Material Science SB RAS), Kemerovo, 650000, Russia \\ kriger@kemsu.ru
}

PACS 61.46. $+w$, 82.33.Vx

DOI 10.17586/2220-8054-2016-7-6-1017-1023

\begin{abstract}
The dependencies of critical energy density and corresponding hot-spot temperature were calculated in terms of thermal model of energetic materials laser initiation for 12 metal nanoparticles in pentaerythritol tetranitrate (PETN) at pulse duration $12 \mathrm{~ns}$. We showed that the critical hot-spot temperature depends mostly on the nanoparticle's radius while its dependence on the specific heat of the metal is much weaker. The equations for the critical parameters of initiation on radius and specific heat of the nanoparticles were derived. The results are essential for the explosive compounds for optical detonator cup optimization.
\end{abstract}

Keywords: pentaerythritol tetranitrate, metal nanoparticles, laser radiation, hot-spot model.

Received: 4 August 2016

\section{Introduction}

The use of pulsed laser methods for the initiation of the explosive processes is under consideration now as a promising replacement for electrical methods of initiation. The main reason is the crucial increasing of safety in explosives utilization and the reduction and minimization of environmental risks and technological disasters. The use of explosives drastically lowers the costs for tunneling works, which determines the increasing scale of their utilization [1]. The most intensively developed way to improve the safety of storage, transportation and use of explosives is the development of energetic materials selectively sensitive to the needed impact [1,2]. Optical detonators based on silver azide [3,4] have minimum thresholds value when initiated with laser pulse, but they are also sensitive to other types of impact (heat, electric spark, etc.). To create selectively sensitive materials to laser radiation, one introduces light-absorbing nanoparticles [5] or the synthesis of new compound with absorption bands matching the wavelength of the radiation sources to the existing transparent explosives [6-8]. The minimum initiation energy density of explosive decomposition of the regular blasting explosives (PETN and RDX) with additives of aluminum $[2,9,10]$, nickel $[10,11]$ and other metals nanoparticles is of the order of $1 \mathrm{~J} / \mathrm{cm}^{2}$, which is more than hundred times less than for pure pressed tablets of this explosives. This is an energy saving method to initiate due to the concentration of thermal energy in "hot-spots" and the implementation of thermal explosion in a microcenter variant. The initiation mechanism based on the energy absorption by small inclusions in the explosives volume was formulated in [12] for heavy metal azides. In [13-15], the model was modernized with optical properties and melting processes of nanoparticles and the matrix. The relevance of modernization and study of the hot-spot model is defined by its fundamental value for the development of the mechanisms of thermal explosion model representations, as well as by the applied one based on the selectively sensitive optical detonator creation.

The purpose of this work is the determination of the critical parameters for the initiation of explosive decomposition reaction calculation in the framework of the hot-spot model of thermal explosion, defining the role of the thermophysical parameters of the nanoparticles' material at the stage of formation and development of the reaction hot-spot and analysis of the results in dimensionless coordinates for the process. The compounds based on regular secondary explosives PETN and the nanoparticles of 12 metals were selected as model systems.

The process of initiating self-accelerating decomposition in transparent explosives and metal nanoparticles of different natures can be divided into several stages: the transfer of energy from the output window of the source of monochromatic radiation to nanoparticles, the absorption of the pulse energy of nanoparticles, heating the nanoparticles and labile matrix with the formation of the explosive decomposition hot-spot. The influence of phase transitions in the nanoparticle and the matrix were considered in [15], where it was shown that the melting has little effect on threshold values for initiation of PETN - aluminum nanoparticle systems. Depending on the material and radius of nanoparticles, the absorption efficiency varies considerably $[14,15]$. The consideration of 
multiple scattering in the sample leads to a substantial increase of illumination in the sample's volume [17-19]. The values of the reflection coefficient from the front surface of the sample, experimentally defined in [20], also change significantly depending on sample parameters and radiation wavelength. The optical effect consideration greatly complicates the mechanism for explosive decomposition, but it is possible to allocate a relatively slow subsystem: heating of the nanoparticles where the ratio of the absorption efficiency coefficients of the nanoparticles is 1 [12], conductive heat transfer and thermal chemical decomposition of explosives. It is rational to take into account the peculiar features of nearly instantaneous propagation and absorption of laser light by metal nanoparticles by later correcting the calculated dependence of the nanoparticles' radii critical parameters on previously defined coefficients (as in $[15,21,22]$ ).

Additional assumptions implicitly used by the authors of the hot-spot model $[12,17]$ are: metal nanoparticles do not have an oxide film; they are in tight contact with the matrix explosives; and do not interact with it chemically. The spherical symmetry originally used by the authors of the model, is due to three circumstances. First, in the case of pressed pellets of explosives, the light falling onto the sample undergoes multiple reflection on the grain boundaries and metal nanoparticles [17-19]. Because of the randomness of the reflection acts and the significantly negative values of the mean cosine of the scattering angle by metal nanoparticles in PETN [23], the light intensity averages over every direction. Second, the absorbed pulse energy, turning into heat, quickly spreads over the nanoparticles' volume, especially when they are not very big (less than $120 \mathrm{~nm}$ ). The values of the thermal diffusivity of metals are much higher than that of PETN, which lead to almost uniform heating of the nanoparticles during the pulse duration $(\sim 10 \mathrm{~ns})$ [24]. Third, with one-dimensional approach it is possible to produce the necessary mathematical calculations with much greater accuracy for a reasonable time. Thus, the use of spherical symmetry is justified. The system of differential equations describing the processes of conductive heat transfer, and heat generation due to chemical decomposition of energetic material, has the form [12]:

$$
\begin{aligned}
& \frac{\partial T}{\partial t}=\alpha\left(\frac{\partial^{2} T}{\partial x^{2}}+\frac{2}{x} \frac{\partial T}{\partial x}\right)+\frac{Q}{C} k_{0} n \cdot \exp \left(-\frac{E}{k_{B} T}\right), \quad x>R, \\
& \frac{\partial n}{\partial t}=-k_{0} n \cdot \exp \left(-\frac{E}{k_{B} T}\right), \quad x>R, \\
& \frac{\partial T}{\partial t}=\alpha_{m}\left(\frac{\partial^{2} T}{\partial x^{2}}+\frac{2}{x} \frac{\partial T}{\partial x}\right), \quad x<R,
\end{aligned}
$$

where $T$ is temperature, $n$ is relative concentration of explosives decreases in the course of the decomposition reaction from 1 to $0, \alpha=1.1 \cdot 10^{-3} \mathrm{~cm}^{2} \mathrm{~s}^{1}$ and $\alpha_{m}$ are thermal diffusivities of the matrix and nanoparticle, $k_{B}$ is Boltzmann constant, $E=165 \mathrm{~kJ} /(\mathrm{mol} \cdot \mathrm{K})$ is energy of activation, $Q=9.64 \mathrm{~kJ} / \mathrm{cm}^{3}$ is heat efficiency of the decomposition, $k_{0}=1.2 \cdot 10^{16} \mathrm{~s}^{-1}$ is pre-exponential factor [14], $=2.22 \mathrm{~J} /\left(\mathrm{cm}^{3} \mathrm{~K}\right)$ is volumetric heat capacity of the explosives with boundary condition for $x=R$ is:

$$
J-\left.C_{m} \alpha_{m} \cdot \frac{\partial T}{\partial x}\right|_{x \rightarrow R-0}+\left.C \alpha \cdot \frac{\partial T}{\partial x}\right|_{x \rightarrow R+0}=0
$$

where $C_{m}$ is volumetric heat capacity of the nanoparticle, $J(t)$ is is the absorbed density of the laser pulse radiation power. Tn terms of the model we neglecting the possible non-ideal thermal contact of the nanoparticle and the explosive [25] and possible diffusion of the explosive material [26].

The facilities based on a neodymium laser typically used for initiation of explosive decomposition have the dependence of the radiation power of the pulse close to the normal distribution function [27]. Taking the maximum intensity of the pulse as the reference time position, we obtain for the quantity $J(t)$ the expression:

$$
J(t)=k_{i} H_{0} \cdot \exp \left(-k_{i}^{2} t^{2}\right) / \sqrt{\pi}
$$

where $k_{i}=\frac{2 \sqrt{\ln (2)}}{t_{i}}$ is a parameter that determines the pulse duration; $H_{0}-$ the pulse energy density. Multipliers of equation (3) normalized the integral of $J(t)$ with respect to time on $H_{0}$. Model of explosive decomposition under initiation by a laser pulse is rational initially to explore in dimensional variables, with a further choice of dimensionless. To determine the critical parameters of explosive decomposition, the system of equations for the model (1-3) was numerically solved on the grid with a variable coordinate step by the method described in [24,28].

The calculations were performed for 12 metals to elucidate the role of thermophysical properties for the material nanoparticles. The values of heat capacities and thermal conductivities of the metals used were taken from [21]. The variation of the nanoparticles radius was carried out over the 10-120 nm range. This interval covers the radii used in the experimental studies of aluminum [2,19] and nickel $[10,11]$ nanoparticles, a typical area radii of noble 
metal nanoparticles, 10-20 nm, by effectively absorbing electromagnetic radiation at the frequencies of plasmon resonance $[22,29]$ and relatively large radii of transition metals at which the radiation of the first harmonic of a neodymium laser is absorbed the most efficiently [23] though the plasmon band is observed in the UV region for aluminum nanoparticles [30].

\section{The method of calculation and results}

The calculation of the critical energy density was carried out using bisection method with the interval reduction achieving up to a relative accuracy of $10^{-8}$. The determination of the system bifurcation point (1)-(3) with such precision requires the minimization of errors associated with the calculation of critical parameters for explosive decomposition initiation and definition of the explosive decomposition parameters close to the bifurcation point [31]. For further analysis, the maximum energy density at which the explosion was not observed $H$ was retained. To consider the contribution of the chemical reaction in the threshold of initiation, the maximum temperature on the surface of the nanoparticles with the energy density $H\left(T_{\max }\right)$ and the time of its occurrence $t\left(T_{\max }\right)$ were calculated. The calculation of the maximum temperature $T_{\max 0}$ for each system at the energy density of $H$ without taking into account the heat flux due to chemical decomposition (installed $k_{0}=0$ ) and the time of appearance of maximum temperature $t\left(T_{\max }\right)$ was subsequently performed.

For 12 selected metals in PETN, we calculated selected characteristics of the process near the bifurcation point. Table 1 presents the results of calculations of $H, T_{\max }, t\left(T_{\max }\right), T_{\max 0}$ and $t\left(T_{\max 0}\right)$ with the radii of nanoparticles of cobalt ranging from $10-120 \mathrm{~nm}$. The critical energy density values significantly depend upon the nanoparticles' radii, but an even more amazing result is the significant dependence of the temperature characteristic of the process on the radius of the nanoparticles. From Table 1, it follows that $T_{\max }$ is significantly higher than $T_{\max 0}$. The temperature difference increases with decreasing nanoparticle radius. For cobalt nanoparticles with a $10 \mathrm{~nm}$ radius and a pulse duration of $12 \mathrm{~ns}$, the difference is around $346 \mathrm{~K}$ and in the limit of large radius is less than $40 \mathrm{~K}$. The dependence $T_{\max 0}(R)$ is well described by the equation:

$$
T_{c}(R)=T_{\infty}+\frac{r_{T}}{R}
$$

where the variable parameters $T_{\infty}$ and $r_{T}$ (4) are determined with approximation of the corresponding dependencies. The values of the variable parameters for the 12 considered metals in the matrix PETN are given in Table 2.

As one can see, the values of $T_{\infty}$ for the 12 metals differ by only $19 \mathrm{~K}$. The parameter $r_{T}$ deviates maximally from the middle value by $2 \%$ only. Consequently, the critical temperature of the reaction hot-spot of explosive decomposition is almost independent on the nature of the metal nanoparticles.

Let us consider the dependence of the critical energy density of the radius and the nature of the nanoparticles. Consider a simplified model for thermophysical processes with heating of nanoparticles in inert matrices. The maximum change by primary hot-spot temperature without considering contribution of chemical decomposition of the matrix could be estimated with the expression $[11,12]$ :

$$
\Delta T=\frac{3}{4 \pi} \cdot \frac{\pi R^{2} H}{C_{m} R^{3}+C\left((R+h)^{3}-R^{3}\right)} .
$$

In the numerator of formula (1), the energy absorbed by the nanoparticle as a result of the pulse action remains, and the denominator estimates the overall heat capacity of the system, involving heating of the matrix layer of thickness $h$ and nanoparticles to the same temperature. The value $h$ is the effective thickness of the heated layer of the matrix, determined by the pulse duration, heat capacity and thermal diffusivity of the matrix, but not the thermophysical properties of the nanoparticles (as the ration $\alpha<<\alpha_{m}$ is fulfilled for all the metals). Using the formula (4), approximating the dependence of the critical temperature of the hot-spot on the nanoparticles' radii without a chemical reaction as $T_{\max 0}$, and dropping off the term proportional to $h^{3}$, we get:

$$
H=\frac{4}{3 R} \cdot\left(T_{\infty}+\frac{r_{T}}{R}-T_{0}\right) \cdot\left[C_{m} R^{2}+3 C h \cdot(R+h)\right] .
$$

Approximation of the calculated dependences $H(R)$ by formula (6) was performed for all 12 selected metals in PETN applying the previously defined fitting parameters $T_{\infty}$ and $r_{T}$ that are given in columns 2 and 3 of Table 2 . The array $h$ is shown in column 4 of Table 2 . From the estimated values of $h$, it follows that they are independent of the nature of the metal nanoparticles: the average value of $h=34.87 \mathrm{~nm}$ and a maximum deviation is only $0.5 \%$. This result is consistent with its physical meaning as the typical thickness of the heated layer.

Using formula (6) we could demonstrate the effect of the metals' specific heat on the dependence of $H(R)$. The coordinates of the minima for the dependences $H(R)$ for 12 metals in PETN $\left(H_{\text {min }}\right.$ and $\left.R_{\text {min }}\right)$ are presented 
TABLE 1. Calculated with the radii of the cobalt nanoparticles $R$ values $H, T_{\max }, t\left(T_{\max }\right)$, $T_{\max 0}, t\left(T_{\max 0}\right)$

\begin{tabular}{|c|c|c|c|c|c|}
\hline$R, \mathrm{~nm}$ & $H, \mathrm{~mJ} / \mathrm{cm}^{2}$ & $T_{\max }, \mathrm{K}$ & $t\left(T_{\max }\right), \mathrm{ns}$ & $T_{\max 0}, \mathrm{~K}$ & $t\left(T_{\max 0}\right), \mathrm{ns}$ \\
\hline 10 & 136.170749 & 1497.06 & 4.0496 & 1150.90 & 1.3178 \\
\hline 15 & 97.928431 & 1360.16 & 6.080 & 1107.83 & 1.9417 \\
\hline 20 & 81.485410 & 1289.6 & 7.5321 & 1088.68 & 2.5232 \\
\hline 25 & 72.908448 & 1245.46 & 8.6159 & 1077.56 & 3.0538 \\
\hline 30 & 68.110572 & 1214.96 & 9.4775 & 1070.86 & 3.4867 \\
\hline 35 & 65.3497462 & 1192.23 & 10.200 & 1066.07 & 3.8931 \\
\hline 40 & 63.8247203 & 1174.39 & 10.722 & 1062.41 & 4.2578 \\
\hline 45 & 63.1029816 & 1159.97 & 11.203 & 1059.51 & 4.6208 \\
\hline 50 & 62.931098 & 1148.01 & 11.495 & 1057.11 & 4.9111 \\
\hline 55 & 63.1510649 & 1137.91 & 11.601 & 1055.09 & 5.2318 \\
\hline 60 & 63.6594571 & 1129.31 & 11.725 & 1053.32 & 5.4625 \\
\hline 65 & 64.3858326 & 1121.89 & 11.692 & 1051.77 & 5.7452 \\
\hline 70 & 65.2806344 & 1115.45 & 11.606 & 1050.37 & 5.9199 \\
\hline 75 & 66.3080204 & 1109.81 & 11.596 & 1049.10 & 6.138 \\
\hline 80 & 67.4414514 & 1104.82 & 11.558 & 1047.95 & 6.3609 \\
\hline 85 & 68.6608745 & 1100.38 & 11.488 & 1046.87 & 6.5691 \\
\hline 90 & 69.9508670 & 1096.38 & 11.465 & 1045.86 & 6.6802 \\
\hline 95 & 71.2993787 & 1092.77 & 11.388 & 1044.92 & 6.8438 \\
\hline 100 & 72.6968651 & 1089.47 & 11.400 & 1044.04 & 7.0616 \\
\hline 105 & 74.1356704 & 1086.45 & 11.316 & 1043.19 & 7.2034 \\
\hline 110 & 75.6095868 & 1083.66 & 11.349 & 1042.39 & 7.3449 \\
\hline 115 & 77.1135275 & 1081.08 & 11.330 & 1041.62 & 7.4714 \\
\hline 120 & 78.6438735 & 1078.68 & 11.316 & 1040.86 & 7.6307 \\
\hline
\end{tabular}

in the last columns of Table 2. Assuming that the dependence $T_{\max 0}(R)$ at relatively large radii $R_{\min }$ corresponding to the minimum $H$, is weak, in this limit, the dependence $H(R)$ will match the radius of most heated nanoparticles [14]:

$$
R_{\min }=\sqrt{\frac{6 \alpha k_{i} C}{C_{m}}} .
$$

Equation (7) leads to a linear dependence of the $R_{\text {min }}$ square on the reverse value of the metal heat capacity $\left(C_{m}\right)$. Fig. 1 shows the dependence of the abscissa of the minimum $R_{\min }$ as a dependence on the metal volume specific heat capacity in the rectifying coordinates. Points in the figure show the data for the metals lead, tin, aluminum, silver, gold, palladium, vanadium, chromium, copper, iron, cobalt, nickel, and their good linear approximation. 
The dependence of the critical energy density and hot-spot temperature...

TABLE 2. Calculated critical parameters of explosive decomposition for PETN with various metal nanoparticles

\begin{tabular}{|c|c|c|c|c|c|}
\hline Metal & $T_{\infty}, \mathrm{K}$ & $r_{T}, \mathrm{~K} \cdot \mathrm{nm}$ & $h, \mathrm{~nm}$ & $H_{m i n}, \mathrm{~mJ} / \mathrm{cm}^{2}$ & $R_{m i n}, \mathrm{~nm}$ \\
\hline $\mathrm{Pb}$ & 1070.45 & 1638.38 & 35.03 & 47.712 & 79.20 \\
\hline $\mathrm{Sn}$ & 1071.39 & 1644.82 & 34.98 & 49.430 & 74 \\
\hline $\mathrm{Al}$ & 1074.31 & 1688.38 & 34.85 & 54.987 & 61.3 \\
\hline $\mathrm{Ag}$ & 1074.35 & 1689.10 & 34.85 & 55.206 & 60.90 \\
\hline $\mathrm{Au}$ & 1074.43 & 1690.08 & 34.85 & 55.352 & 60.60 \\
\hline $\mathrm{Pd}$ & 1075.68 & 1703.11 & 34.81 & 58.068 & 56 \\
\hline $\mathrm{V}$ & 1076.33 & 1709.01 & 34.79 & 58.559 & 55.20 \\
\hline $\mathrm{Cr}$ & 1076.03 & 1704.22 & 34.81 & 59.930 & 53.30 \\
\hline $\mathrm{Cu}$ & 1075.99 & 1700.82 & 34.83 & 61.145 & 51.60 \\
\hline $\mathrm{Fe}$ & 1076.73 & 1702.26 & 34.82 & 61.802 & 50.80 \\
\hline $\mathrm{Co}$ & 1076.41 & 1698.39 & 34.84 & 62.928 & 49.40 \\
\hline $\mathrm{Ni}$ & 1076.51 & 1693.51 & 34.85 & 64.097 & 48.10 \\
\hline
\end{tabular}

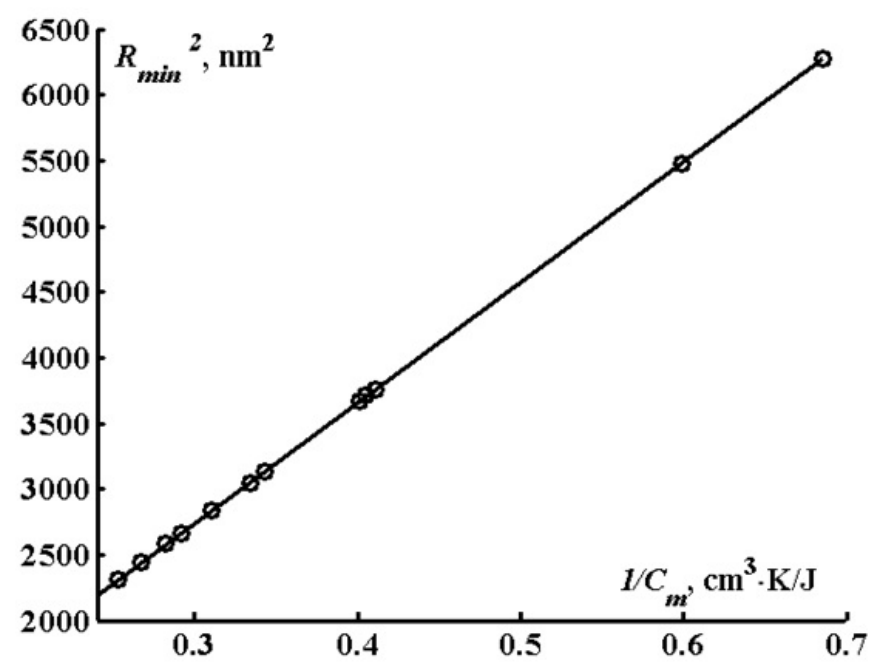

FIG. 1. The dependence of the square $R_{\text {min }}$, from the reverse value of the metal heat capacity $\left(C_{m}\right)$ with pulse width was $12 \mathrm{~ns}$. The dots are the data for the metals: lead, tin, aluminum, silver, gold, palladium, vanadium, chromium, copper, iron, cobalt, nickel. Line-approximation of the line passing through the origin

\section{Conclusion}

Using the characteristics of 12 metals in the present work allowed us to investigate the effect of nanoparticles' specific heat in the range from 1.46 (lead) to $3.96 \mathrm{~J} /\left(\mathrm{cm}^{3} \cdot \mathrm{K}\right.$ ) (nickel) on the main characteristics of the process of laser initiation. The obtained analytical equations quantitatively describing the results of the calculations allow us to predict the influence of specific heat over a wide range that it is necessary to expand the range of materials considered as promising additives for the selective sensitivity of explosives by laser radiation.

Currently, the refinement of the hot-spot model for the laser initiation of thermal explosion of energetic materials containing metal nanoparticles occurs in a number of directions that span the optical and thermophysical processes. For this reason, the comparison with experiment of the results of this study is difficult. Previously it was shown [9] that taking into account the optical properties of individual metal nanoparticles allows us to 
reduce considerably the differences of the absolute theoretical and experimental values for the critical energy density. The last quantity can be reliably predicted if we know the kinetic parameters for the decomposition reaction in the temperature region in which a hot-spot is formed. Direct measurement of the rate constant over this temperature range is difficult, therefore, reasonable extrapolations from the low temperature region generally used may not always be applicable. Alternatively, the obtained expressions allow one to predict correctly the effect of the thermophysical parameters of nanoscale additives, which is essential in the development of new energetic materials.

\section{Acknowledgements}

This work was supported by Ministry of Education and Science of the Russian Federation (governmental project No. 2014/64) and Russian Foundation for Basic Research for the financial support (grant 14-03-31648).

\section{References}

[1] Chernai A.V., Sobolev V.V., Chernai V.A., Ilyushin M.A., Dlugashek A. Laser Ignition of Explosive Compositions Based on di-(3hydrazino-4-amino-1,2,3-triazole)-Copper(II) Perchlorate. Combustion, Explosion and Shock Waves, 2003, 39(3), P. 335-339.

[2] Aduev B.P., Nurmukhametov D.R., Furega R.I., Zvekov A.A., Kalenskii A.V. Explosive decomposition of PETN with nanoaluminum additives under the influence of pulsed laser radiation at different wavelengths. Russian Journal of Physical Chemistry B, 2013, 7(4), P. 453-456.

[3] Kriger V.G., Kalenskii A.V., Zakharov Yu.A., Tsipilev V.P. Mehanizm tverdofaznoj cepnoj reakcii. Materialovedenie, 2006,9 , P. 14-21.

[4] Kriger V.G., Kalenskii A.V., Zvekov A.A. Relaxation of electronically excited products of solid-state reactions in the crystal lattice. Russian Journal of Physical Chemistry B, 2012, 6(1), P. 15-18.

[5] Aduev B.P., Belokurov G.M., Nurmukhametov D.R., Nelyubina N.V. Photosensitive material based on PETN mixtures with aluminum nanoparticles. Combustion, Explosion, and Shock Waves, 2012, 48(3), P. 361-366.

[6] Greenfield M.T., McGrane S.D., Bolme C.A., Bjorgaard J.A., Nelson T.R., Tretiak S., Scharff R.J. Photoactive high explosives: linear and nonlinear photochemistry of petrin tetrazine chloride. Journal of Physical Chemistry A, 2015, 119(20), P. 4846-4855.

[7] Evers J., Gospodinov I., Joas M., Klapötke T.M., Stierstorfer J. Cocrystallization of photosensitive energetic copper(II) perchlorate complexes with the nitrogen-rich ligand 1,2-di(1H-tetrazol-5-yl)ethane. Inorganic Chemistry, 2014, 53(21), P. 11749-11756.

[8] Gerasimov S.I., Ilyushin M.A., Kuz'min V.A. A laser diode beam initiates a high-energy mercury perchlorate-polymer complex. Technical Physics Letters, 2015, 41(4), P. 338-340.

[9] Kalenskii A.V., Zvekov A.A., Anan'eva M.V., Zykov I.Yu., Kriger V.G., Aduev B.P. Influence of laser wavelength on the critical energy density for initiation of energetic materials. Combustion, Explosion, and Shock Waves, 2014, 50(3), P. 333-338.

[10] Aduev B.P., Nurmukhametov D.R., Furega R.I., Zvekov A.A. Controlling pentaerythrite tetranitrate sensitivity to the laser effect through the addition of nickel and aluminum nanoparticles. Russian Journal of Physical Chemistry B, 2014, 8(3), P. 352-355.

[11] Zvekov A.A., Ananyeva M.V., Kalenskii A.V., Nikitin A.P. Regularities of light diffusion in the composite material pentaerythriol tetranitrate-nickel. Nanosystems: Physics, Chemistry, Mathematics, 2014, 5(1), P. 685-691.

[12] Alexandrov E.I., Tsipilev V.P. Effect of the pulse length on the sensitivity of lead azide to laser radiation. Combustion, Explosion and Shock Waves, 1984, 20(6), P. 690-694.

[13] Kalenskii A.V., Kriger V.G., Zvekov A.A., Grishaeva E.A., Zykov I.Yu, Nikitin A.P. The Microcenter Heat Explosion Model Modernization. Izvestija vysshih uchebnyh zavedenij. Fizika, 2012, 55(11-3), P. 62-65.

[14] Kriger V.G., Kalenskii A.V., Zvekov A.A., Zykov I.Yu., Aduev B.P. Effect of laser radiation absorption efficiency on the heating temperature of inclusions in transparent media. Combustion, Explosion, and Shock Waves, 2012, 48(6), P. 705-708.

[15] Aduev B.P., Anan'eva M.V., Zvekov A.A., Kalenskii A.V., Kriger V.G., Nikitin A.P. Miro-hotspot model for the laser initiation of explosive decomposition of energetic materials with melting taken into account. Combustion, Explosion and Shock Waves, 2014, 50(6), P. 704-710.

[16] Galkina E.V., Radchenko K.A. The model of initiation of composites PENT - Tin by the pulse Nd: YAG laser. Nauka-Rastudent.ru, 2015. http: //nauka-rastudent.ru/21/2917/.

[17] Aleksandrov E.I., Tsipilev V.P. Characteristics of the optical regime in the volume of a semiinfinite layer of diffusely scattering medium under illumination by a directed beam with finite aperture. Russian Physics Journal, 1989, 31(10), P. 789-794.

[18] Zvekov A.A., Kalenskii A.V., Aduev B.P., Ananyeva M.V. Calculation of the optical properties of pentaerythritol tetranitrate-cobalt nanoparticle composites. Journal of Applied Spectroscopy, 2015, 82(2), P. 213-220.

[19] Aduev B.P., Nurmukhametov D.R., Belokurov G.M., Zvekov A.A., Kalenskii A.V., Nikitin A.P., Liskov I.Yu. Integrating sphere study of the optical properties of aluminum nanoparticles in tetranitropentaerytrite. Technical Physics, 2014, 59(9), P. 1387-1392.

[20] Aduev B.P., Nurmukhametov D.R., Liskov I.Yu., Kalenskii A.V., Anan'eva M.V., Zvekov A.A. Characteristics of the initiation of the explosive decomposition of PETN by the second-harmonic pulsed radiation of a neodymium laser. Russian Journal of Physical Chemistry B, 2015, 9(6), P. 915-920.

[21] Ananyeva M.V., Zvekov A.A., Zykov I.Yu., Kalenskii A.V., Nikitin A.P. Promising compounds for the cap of optical detonator. Perspektivnye materialy, 2014, 2, P. 5-12.

[22] Lukatova S.G. Calculation of the PETN-gold composites' absorptivity for the second harmonic of the Nd:YAG laser. Mezhdunarodnoe nauchnoe izdanie Sovremennye fundamental'nye i prikladnye issledovanija, 2014, 1(12), P. 95-98.

[23] Ivashenko G.J. The regularities of light scattering from the Nd:YAG first harmonic of nickel nanoparticles in PETN. Actualscience, 2015, 1(3), P. 63-67.

[24] Kriger V.G., Kalenskii A.V., Zykov I.Y., Nikitin A.P., Zvekov A.A. Heat-transfer processes upon laser heating of inert-matrix-hosted inclusions. Thermophysics and Aeromechanics, 2013, 20(3), P. 367-374.

[25] Glushkov D.O., Kuznetsov G.V., Strizhak P.A. Ignition of a composite propellant by a hot particle under conditions of a nonideal thermal contact. Russian Journal of Physical Chemistry B, 2015, 9(4), P. 631-636. 
[26] Chumakov Yu.A., Knyazeva A.G. Initiation of reaction in the vicinity of a single particle heated by microwave radiation. Combustion, Explosion, and Shock Waves, 2012, 48(2), P. 144-150.

[27] Odincova O.V., Ivashenko G.J. Temporal impulse shape of the first harmonic of the ND:YAG laser. Mezhdunarodnoe nauchnoe izdanie Sovremennye fundamental'nye i prikladnye issledovanija, 2015, 2(17), P. 43-48.

[28] Zykov I.Yu., Kalenskii A.V. Application program package to simulate the kinetics of the explosive decomposition initiated by laser pulse in energetic material containing metal nanoparticles. Aspirant, 2015, 2, P. 73-77.

[29] Kalenskii A.V., Zvekov A.A., Nikitin A.P., Anan'eva M.V., Aduev B.P. Specific features of plasmon resonance in nanoparticles of different metals. Optics and Spectroscopy, 2015, 118(6), P. 978-987.

[30] Blaber M.G., Arnold M.D., Harris N., Ford M.J., Cortie M.B. Plasmon absorption in nanospheres: A comparison of sodium, potassium, aluminium, silver and gold. Physica B: Condensed Matter, 2007, 394(2), P. 184-187.

[31] Radchenko K.A. The effect of the relative error on the accuracy of mathematical modeling. Nauka-rastudent.ru, 2015. http: //naukarastudent.ru/24/3131/. 